\title{
Kampus Mengajar: Upaya Pendampingan Pendidikan Era Pandemi Covid-19 di Desa Kalampadu Ogan Ilir
}

\author{
Kampus Mengajar: Educational Assistance Efforts in the Era of the Covid-19 Pandemic in \\ Kalampadu Ogan Ilir Village
}

Yulasteriyani ${ }^{*}$
Gita Isyanawulan ${ }^{*}$
Isma Nurillah ${ }^{2}$
1Department of Sociology, Universitas
Sriwijaya, Palembang, South
Sumatera, Indonesia
2Department of Law, Universitas
Sriwijaya, Palembang,
Sumatera, Indonesia
Received: December 2020
Accepted: May 2021
Published: June 2021
Kata Kunci
Covid-19
Kualitas pendidikan
Media pembelajaran
Pendidikan pedesaan
Keywords:
Covid-19
Education quality
Learning Media
Rural education

\begin{abstract}
Abstrak
Pengabdian ini dilatar belakangi oleh fenomena sosial-budaya pendidikan di Desa Kalampadu, sejak sistem sekolah jarak jauh memunculkan berbagai masalah sosial baru. Kualitas sumber daya sekolah, sumber daya orang tua, media daring, hingga akses internet tidak mendukung proses pembelajaran menyebabkan anak-anak disini sulit memahami materi pelajaran sekolah. Masalah sosial-budayapendidikan ini tidak boleh dibiarkan tanpa upaya penangan masalah karena anak-anak bangsa adalah harapan dan penerus di masa depan Indonesia sejahtera. Tim pengabdian kepada masyarakat Unsri ikut membantu pemecahan masalah pendidikan ini dengan melakukan sosialisasi dan internalisasi sosial-budaya-pendidikan. Kegiatan pengabdian masyarakat ini dilakukan di Balai Desa, Desa Kalampadu yang melibatkan 32 orang peserta terdiri dari orang tua, guru, siswa, tokoh masyarakat dan pemerintah desa. Metode kegiatan ini dilakukan dengan penyampaian materi dan praktek langsung kepada peserta kegiatan pengabdian. Hasil rangkaian kegiatan pengabdian ini sarat dengan praktek dari teori struktural fungsional Parsons. Setiap rangkaian acara dari awal sampai akhir sangat cocok dengan skema AGIL dalam proses sosialisasi dan internalisasi nilai-norma pendidikan. Kata sambutan sebagai proses re-adaptasi, penyampaian materi sesuai dengan skema re-integrasi, serta proses tanya-jawab dan interaktif menerapkan semua unsur adapatasi-pencapaian tujuan-integrasi-pemeliharaan pola. Kegiatan pengabdian ini juga bagian dari integrasi sistem sosial-budaya pendidikan menuju sistem sosial pendidikan yang ideal dan sejahtera.
\end{abstract}

\begin{abstract}
This service is motivated by the socio-cultural phenomenon of education in Kalampadu Village since the distance school system has created new social problems. The quality of school resources, parental resources, online media, and internet access does not support the learning process, causing children to find it challenging to understand school subject matter. This socio-cultural-educational problem should not be left without efforts to solve the problem because the nation's children are the hope and successor in a prosperous future of Indonesia. The Unsri community service team helped solve this educational problem by conducting socialization and internalization of socio-cultural-educational. This community service activity was carried out at the Village Hall, Kalampadu Village, involving 32 participants consisting of parents, teachers, students, community leaders, and the village government. This method is carried out by delivering material and direct practice to the participants of service activities. The results of these activities are full of practice from Parsons' structural, functional theory. Every series of events from beginning to end fits perfectly with the AGIL scheme in socializing and internalizing educational norms. Welcoming remarks as a process of re-adaptation, delivery of material according to the re-integration scheme, and a question-and-answer and interactive process is applying all elements of adaptation-achievement of goals-integration-maintenance of patterns. This service activity integrates the socio-cultural system of education towards an ideal and prosperous educational, social system.
\end{abstract}




\section{PENDAHULUAN}

Pendidikan merupakan satu dari beberapa sub-struktur sosial terpenting dalam struktur sosial budaya masyarakat. Suatu negara dapat dikatakan maju dan sejahtera apabila memiliki kualitas sumber daya manusia yang baik. Pendidikan menjadi indikator kualitas sumber daya manusia, semakin tinggi angka pertisipasi sekolah dalam suatu negara semakin menunjukan negara tesebut maju (Endaryono \& Djuhartono, 2017). Isu pendidikan dianggap sangat penting sehingga dalam isu SDGs diangkat menjadi poin penting untuk dilakukan pendidikan berkelanjutan. Setiap orang berhak mendapatkan pendidikan dan pendidkan tanpa membeda-bedakan status sosial budaya. Pembangunan bidang pendidikan menjadi tujuan jangka panjang seluruh negara di dunia, dengan memastikan pendidikan berkualitas yang inklusif dan adil serta mempromosikan kesempatan belajar sepanjang hayat untuk semua (Maria \& Chinemerem, 2019).

Upaya pemerintah- non pemerintah, daerah- nasionalinternasional, serta peraturan- program pendidikan sudah dan terus digalakkan demi mencapai pendidikan yang ideal. Upaya-upaya peningkatan pendidikan berhasil meningkatkan kualitas pendidikan bangsa terbukti dengan angka pastisipasi sekolah semakin tahun semakin meningkat. Deretan peningkatan angka partisipasi sekolah tidak seta-merta diiringi kualitas sumber daya manusia karena kuantitas berbading terbalik dengan kualitas. Perbandingan ini lebih sangat mencolok apabila disandingkan antara pendidikan kota dengan pendidikan kota, baik pada kultural maupun struktural. Angka partisipasi pendidikan setiap daerah memiliki perbedaan bergantung bagaimana sosial budaya ekonomi masyarakat (Basrowi \& Juariyah, 2010; Farida, 2013). Berdasarkan data Badan Pusat Statistik Sumatera Selatan, terdapat angka pastisipasi sekolah terendah (usia 16-18 tahun) tahun 2018 di Provinsi Sumsel terdapat di Kabupaten Banyuasin (55,82\%), Ogan Komering Mir (60,17\%), Muara Enim (65,39\%), serta Ogan $\operatorname{lir}(66,45 \%)$. Angka partisipasi sekolah ini berada dibawah angka rata-rata se Provinsi Sumsel yaitu sebesar 69, 65 \% (Herzog \& Pittman, 1995; Hannum et al., 2009). Dewasa ini dunia dan Indonesia khususnya mengalami culture shock akibat fenomena covid-19. Dunia pendidikan salah satu lembaga dan institusi terpenting masyarakat ini ikut mengalami dampak covid-19 (Asmuni, 2020). Masyarakat mengalami culture shock yaitu pendidkan sistem daring anomie bagi banyak masyarakat. Modernisasi dan teknologi global tidak serta-merta diterima cepat disetiap lapisan sosial budaya masyarakat Indonesia. Akibat perubahan sosial yang cepat ini melahirkan realitas sosial sekaligus masalah sosial baru di dunia pendidikan (Cahyani et al., 2020).

Realitas sosial gap pendidikan desa-kota semakin parah sejak era pandemi covid-19. Karakteristik masyarakat pedesaan khususnya desa tradisional yang masih gagap pengetahuan dan teknologi menghambat proses pendidikan di era pandemi ini. Masyarakat yang paling merasakan masalah ini adalah anak-anak di pedesaan. Fenomena covid-19 memiliki permasalahan sendiri diluar dari permasalahan yang lain. Masyarakat desa masih banyak yang tidak memiliki akses pendidikan daring yang disebabkan oleh tidak memiliki handphone, gagap teknologi, akses internet dan kontrol orang tua siswa. Hal ini menjadi penghambat utama dunia pendidikan di pedesaan yang mungkin saja tidak ikut dirasakan anak-anak sekolah di kota yang sudah lebih melek teknologi, ekonomi, internet serta sumber daya manusia orang tua yang memadai (Rachmawati et al., 2020).

Masalah sosial pendidikan di atas sangat mirip sekali dengan realitas sosial masyarakat pedesaan di Desa Kalampadu Kecamatan Muara Kuang Kabupaten Ogan 
Mir Sumatera Selatan. Anak-anak usia sekolah di desa ini mengalami kendala yang sangat krusial dan perlu dicarikan solusi dan penangan serius. Mengingat semua anak berhak mendapatkan pendidikan dan pelayanan yang baik dari pemerintah dan masyarakat secara umum. Meminjam konsep teori pendidikan, dimana lembaga pendidikan yang baik harusnya memberikan mafaat kepada lingkungan terdekat dengan administrasi wilayah atau geografi dimana lembaga pendidkan itu didirikan. Desa Kalampadu adalah desa secara geografis sangat dekat sekali dengan Kota Indralaya dan kampus Universitas Sriwijaya sehingga pendidikan tinggi harus responsip masalah-masalah ini.

Tridarma perguruan tinggi menjadi indikator utama untuk mendukung pengabdian dan pendampingan pendidikan masyarakat pedesaan ini. Universitas Sriwijaya (Unsri) satu-satunya harapan warga masyarakat Kabupaten Ogan Mir mengingat pusat pendidikan Unsri berada di kabupaten ini. Realitanya anak-anak usia sekolah masih sangat tidak familiar dengan perguruan tinggi ini apalagi untuk kuliah disini, tidak tahu apa yang menjadi penyebabnya mengapa masih banyak orang-orang belum akrab dengan Unsri. Fenomena ini menjadi penting ditinjaklanjuti untuk bagaimana nanti masyarakat tidak hanya akrab dengan Unsri akan tetapi mencintai dan menyayangi Unsri yang pada dasarnya sangat banyak memberikan manfaat bagi masyarakat bangsa dan negara tercinta ini.

Berdasarkan analisis situasi sosial-budaya-pendidikan di atas, maka diangkat tema/judul pengabdian kepada masyarakat tentang 'Kampus Mengajar: Upaya Pendampingan Pendidikan Era Pandemi Covid-19 di Desa Kalampadu Ogan Mir'. Rumusan masalah yang dapat dikemukakan adalah pendampingan belajar bagi anak-anak sekolah Era Pandemi Covid-19 di Desa Kalampadu Ogan Ilir.

\section{METODOLOGI}

Kegiatan pengabdian kepada masyarakat yang dilakukan oleh tim dosen Unsri ini bertujuan untuk memberikan pendampingan belajar bagi anak-anak sekolah Era Pandemi Covid-19 di Desa Kalampadu Ogan Ilir. Pemberian pemahaman dan pemberdayaan pendidikan ini diharapkan mampu mewujudkan masyarakat Indonesia yang cerdas berakhlak dan ikut memajukan bangsa negara RI tercinta. Melalui pengabdian dan bimbingan belajar ini diharapkan dapat mempengaruhi dan membentuk karakter sosialbudaya-pendidkan siswa-siswa yang cerdas, berakhlak dan berguna bagi kemajuan bangsa dan negara. Kualitas sumber daya manusia yang baik menjadi sistem sosial budaya yang nantinya dapat mendorong sistem masyarakat Indonesia unggul, mandiri dan berdaya saing global.

Kegiatan ini dilaksanakan dengan metode bertahap, yakni tahap persiapan, tahap pelaksanaan, dan tahap pelaporan. Tahap persiapan meliputi kegiatan pengamatan, perizinan serta studi pustaka. Tahap pelaksanaan terdiri dari pengabdian sosialisasi kepada anak-anak sekolah mengenai pendidikan, mendampingi dan menginternalisasikan nilai norma pendidikansosial-budaya. Tahap Pelaporan mencakup penyusunan laporan, seminar dan pembahasan, perbaikan, dan pengumpulan laporan.

Tabel I. Tahapan metode kegiatan pengabdian

\begin{tabular}{|c|c|c|}
\hline No & $\begin{array}{c}\text { Tahapan } \\
\text { Pengabdian }\end{array}$ & Kegiatan Pengabdian \\
\hline 1 & Tahap 1 & $\begin{array}{l}\text { 1. Menulis proposal pengabdian } \\
\text { 2. Studi pustaka } \\
\text { 3. Observasi lapangan }\end{array}$ \\
\hline 2 & Tahap 2 & $\begin{array}{l}\text { 4. Sosialiasi dan internalisasi isu } \\
\text { pengabdian } \\
\text { 5. Internalisasi dan praktek media } \\
\text { pembelajaran via android }\end{array}$ \\
\hline 3 & Tahap 3 & $\begin{array}{l}\text { 6. Menulis laporan pengabdian } \\
\text { 7. Seminar, pembahasan dan } \\
\text { perbaikan } \\
\text { 8. Mengumpulkan laporan penelitian } \\
\text { 9. Budaya belajar yang masif pada } \\
\text { siswa-siswi lokus pengabdian }\end{array}$ \\
\hline
\end{tabular}




\section{HASIL DAN PEMBAHASAN}

\section{Tahapan pelaksanaan kegiatan pengabdian}

Pelaksanaan kegiatan pengabdian kepada masyarakat ini yang berjudul Kampus Mengajar: Upaya Pendampingan Pendidikan di Era Pandemi Covid-19 di Desa Kalampadu Kabupaten Ogan Ilir, dilaksanakan pada hari Jumat 20 November 2020 di Kantor Balai Desa Desa Kalampadu Kabupaten Ogan Ilir. Adapun jumlah peserta yang mengikuti kegiatan ini adalah berjumlah 32 orang, terdiri dari 5 orang siswa-siswi SDN 08 Muara Kuang, 2 orang guru SDN 08 Muara Kuang, 2 orang guru PAUD, 2 orang guru TPA, 3 orang tokoh masyarakat, 2 orang karang taruna, 10 orang perangkat desa, serta 6 orang kader posyandu dan lansia. (Yulasteriyani, 2018).

Pelaksanaan kegiatan pengabdian kepada masyarakat ini dilakukan di Kantor Balai Desa, Desa Kalampadu Kabupaten Ogan Ilir dengan susunan acara kegiatan sebagai berikut:

1. Pembukaan

2. Sambutan dari tim pengabdian masyarakat Universitas Sriwijaya

3. Sambutan dari kepala desa Desa Kalampadu

4. Penyampaian materi pengabdian oleh tim pengabdian masyarakat Unsri

5. Interaktif dan tanya jawab materi pengabdian masyarakat dengan peserta pengabdian

6. Praktek menggunakan media pembelajaran di android

7. Pemberian hadiah

8. Penyerahan plakat

9. Penutupan

Susunan acara pertama, acara pengabdian masyarakat di buka oleh MC Ibu Isma dengan pembukaan salam dan basmallah. Pembawa acara memandu jalannya acara ini dari awal pembukaan hingga penutupan.

Kedua, dilanjutkan dengan sambutan oleh tim pengabdian kepada masyarakat Unsri dimana disampaikan salam perkenalan, tujuan serta ucapan terimakasih kepada pihak pemerintah desa dan peserta yang telah berkenan menerima dan menyambut tim Unsri dalam pelaksanaan kegiatan pengabdian kepada masyarakat. Tahap kedua ini tim pengabdian masyarakat telah memperkenalkan tujuan dan inti dari kegiatan dilakukan, hal ini ada titik awal proses sosialisasi dan internalisasi nilai norma pendidikan kepada peserta pengabdian. Kegiatan ini sudah memasuki skema AGIL dari pemikiran Parsons, dimana kata sambutan yang disampaikan sangat sarat dengan proses pencapaian tujuan (goal attainment). Peserta diarahkan untuk memahami apa, bagaimana, serta seperti apa nilai-norma pendidikan yang baik untuk mencapai target pendidikan yang baik.

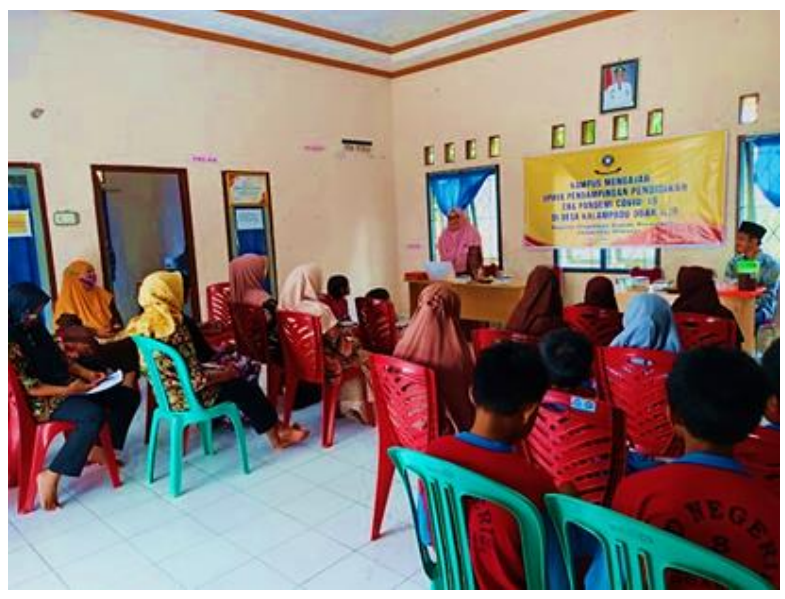

Gambar 1. Kata Sambutan dari Tim Pengabdian Kepada Masyarakat Unsri

Ketiga, susunan acara dilanjutkan dengan kata sambutan lagi oleh kepala desa Desa Kalampadu. Bapak kepala desa sangat antusias menyampaikan sambutan, penerimaan sekaligus membuka jalannya acara kegiatan pengabdian ini.

Keempat, setelah sambutan-sambutan dilakukan, beranjak kepada acara inti yaitu penyampaian materi pengabdian kepada masyarakat. Penyampaian materi dilakukan oleh ibu Yulasteriyani, M,Sos dan Ibu Isma Nurillah, S.H., M.H. dengan sangat interaktif, kreatif, 
motivasi, serta dengan penyampaian bahasa lokal dan indoensia. Kegiatan ini berjalan dengan sangat baik terbukti dengan interaktif peserta dengan tim pengabdian. Ada beberapa siswa dan peserta maju kedepan unjuk diri serta ada yang bertanya dengan baik dan antusias.

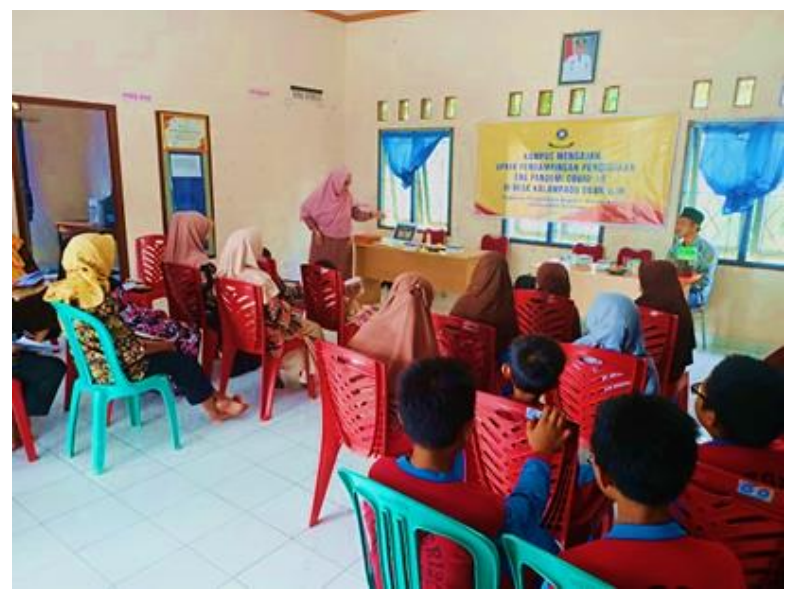

Gambar 2. Penyampaian Materi dan Praktek oleh ibu Yulasteriyani, M.Sos.

Tim pengabdian masyarakat menyampaikan materi merupakan bentuk re-adaptasi nilai norma pendidikan, para peserta dipahamkan tentang kesadaran pendidikan. Pendidikan bukan hanya proses transformasi ilmu tetapi juga usaha sadar untuk berpengetahuan luar serta berakhlak mulia. Para peserta yang terdiri dari guru, siswa, dan tokoh masyarakat dipahamkan, ditanamkan, dan dipraktekkan untuk melakukan proses belajar-mengajar dengan efektif dan efesien (Muttaqin \& Wardana, 2018; Zid \& Alkhudri, 2016; Rasyid, 2015).

Kelima, yaitu sesi interaktif dan tanya-jawab, menindaklanjuti dari penyampaian materi dari tim pengabdian masyarakat, sesi ini para peserta tidak dengan berdiam diri setelah selesai materi disampaian, mereka sesekali melemparkan pertanyaan dan berinteraksi kepada para tim pengabdian serta interaktif dengan para peserta yang lain.

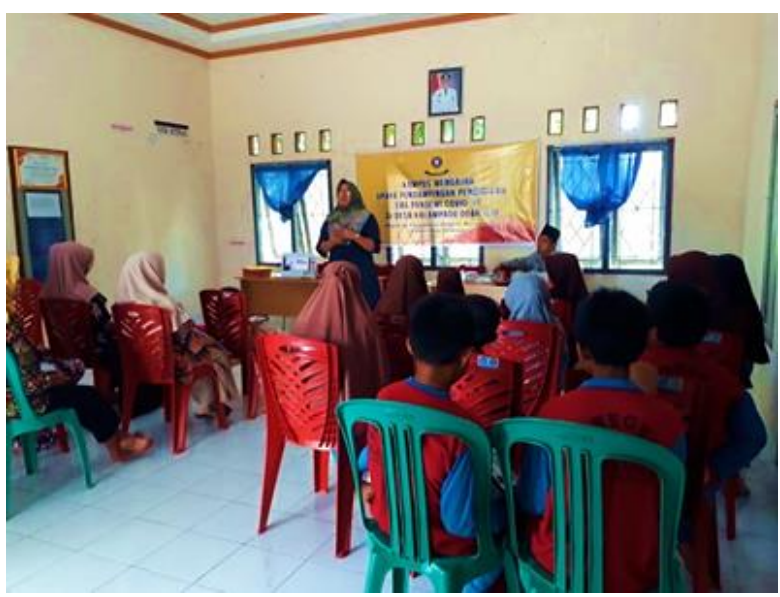

Gambar 3. Kegiatan Tanya-Jawab dan Praktek oleh ibu Isma Nurillah, S.H., M.H.

Sesi tanya jawab dan searing adalah bentuk re-adaptasi; re-pencapaian tujuan; re-integrasi; serta re-pembiasaan pola dalam sistem sosial-budaya-pendidikan masyarakat (Ritzer, 2010; Niko \& Yulasteriyani, 2020). Tahap ini semua skema Parson dipakai untuk proses sosialisasi dan internalisasi nilai norma pendidikan. Peserta yang bertanya dan sharing memiliki keinginantahuan yang besar untuk dapat melakukan belajar-mengajar sesuai dengan pendidikan ideal.

Kegiatan keenam adalah kegiatan praktek menggunakan media pembelajaran di handphone android baik melalu online maupun offline. Diantara media pembelajaran yang ditawarkan tim pengabdian adalah rumah belajar, google classroom, dan Ruangguru. Media pembelajaran yang dikenalkan kepada peserta diharapkan mampu dipraktekkan dalam proses belajarmengajar. Praktek kegiatan ini cukup berjalan lancar karena siswa, orang tua, guru dan peserta lainya sudah terbiasa menggunakan android. Proses internalisasi ini dalam konteks struktural fungsional Parsons sama dengan bentuk adaptasi dan pencapaian tujuan. Siswa, guru, dan orang tua akan memiliki media belajar yang dapat membantu proses belajar dan mengajar agar kegiatan belajar sistem jarak jauh tidak begitu berarti menghambat kualitas pendidikan murid. Sikap perilaku belajar ini akan menjadi pola pembelajaran yang baik 
bagi anak, sehingga dapat mewujudkan budaya belajar dan pendidikan yang sesuai dengan cita-cita bangsa.

Subsistem pendidikan yang baik adalah sumbangsi bagi sistem sosial dan struktur sosial masyarakat dan bangsa yang baik. Budaya belajar yang menyenangkan dan berkualitas adalah re-adaptasi, re-fungsional, serta reperbaikan dari sistem-sistem pendidikan yang selama ini kurang baik. Jika pendidikan baik diharapkan lembaga/pranata sosial yang lain juga ikut baik, sehingga upaya pencerdasan kehidupan bangsa dan mensejahterakan rakyat akan dapat direalisasikan.

Tahap ketujuh dan kedelapan, yaitu proses penyerahan hadiah kepada kepala desa Desa Kalampadu. Ucapan terimakasih dan kepedulian akan kebutuhan kegiatankegitan di kantor desa, maka diberikan hadiah dari tim pengabdian kepada masyarakat Unsri. Tahapan pemberian hadiah dilanjutkan dengan prosesi penyerahan plakat pengabdian kepada kepala desa. Pemberian plakat ini sebagai bentuk apresiasi dan kenang-kenangan dari tim kepada pemerintah desa. Kegiatan ini diharapkan masyarakat agar bisa dilakukan kembali, mereka merasa terbantu dan bersemangat mengikuti kegiatan pengabdian. Isi dan subsistensi pengabdian mendapatkan respons dari masyarakat, artinya proses sosialisasi dan internalisasi berjalan lancar tanpa kendala berarti, sehingga diarapkan kegiatan pendidikan di desa ini dapat berjalan lancar dan baik.

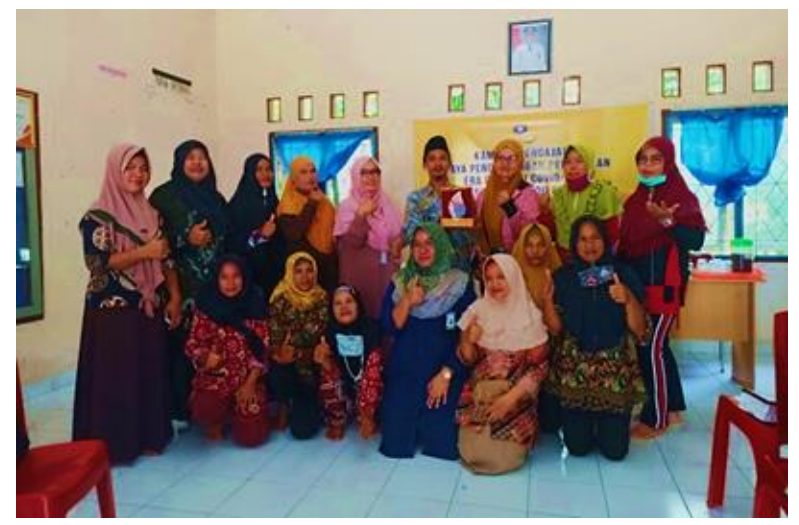

Gambar 4. Penyerahan Hadiah dan Plakat kepada Bapak Kepala Desa
Sesi terakhir penutup, acara ini ditutup dengan mengucap lafal Alhamdulillah serta doa. Doa dilakukan untuk mendapatkan keberkahan dari semua rangkaian acara pengabdian ini, agar semua proses sosialisasi dan internalisasi yang dilakukan dari awal sampai akhir dapat dipraktekkan dalam proses belajar-mengajar. Memohon keberkahan agar kegiatan pengabdian kepada masyarakat ini membantu integrasi nilai norma pendidikan agar tercipta sistem sosial yang lebih teratur dan sejahtera (fungsional) dibandingkan saat ini (Yulasteriyani et al., 2019).

\section{Materi Media Pembelajaran melalui Android}

Secara umum masyarakat Desa Kalampadu sudah tersentuh dengan dunia teknologi online, akan tetapi penggunaan internet hanya sebatas untuk hiburan seperti media sosial dan game online/offline. Realitanya banyak orang tua murid dengan segala upaya membelikan anak-anak mereka handphone android untuk keperluan belajar daring, namun HP yang dimiliki justru disalahgunakan dominan dipakai untuk game, TikTok, dan media sosial lainnya.

Kegiatan pengabdian ini salah satu kontrol sosial untuk para orang tua, guru, dan siswa dalam memahami nilainorma pendidikan. Salah satu bentuk nyata kegiatan ini ialah praktek penggunaan media pembelajaran seperti rumah belajar, Ruangguru, dan google classroom. Media pembelajaran online ini sebagai re-adaptasi, re-integrasi, pencapaian tujuan pendidikan masa new normal covid19.

Aplikasi Rumah Belajar telah dibuat dan dikembangkan oleh Pustekkom Kemendikbud sejak tahun 2011 sebagai salah satu portal pembelajaran berbasis web yang berisi berbagai layanan pembelajaran, baik untuk anak sekolah senjang pendidikan dasar, SMP, SMA, SMK dan sekolah inkusif (Utami \& Dewi, 2020). Salah satu media online yang disosialisasikan adalah rumah belajar dibawah pengembangan Kemendikbud yang fokus pada bidang 
pendidikan. Aplikasi Rumah Belajar terdapat beberapa fitur utama yaitu sumber belajar, kelas digital, bank soal, laboratorium maya, modul digital, peta budaya, wahana jelajah angkasa, pengembangan keprofesian berkelanjutan serta buku sekolah elektronik (BSE) (Ariati \& Andriani, 2020).

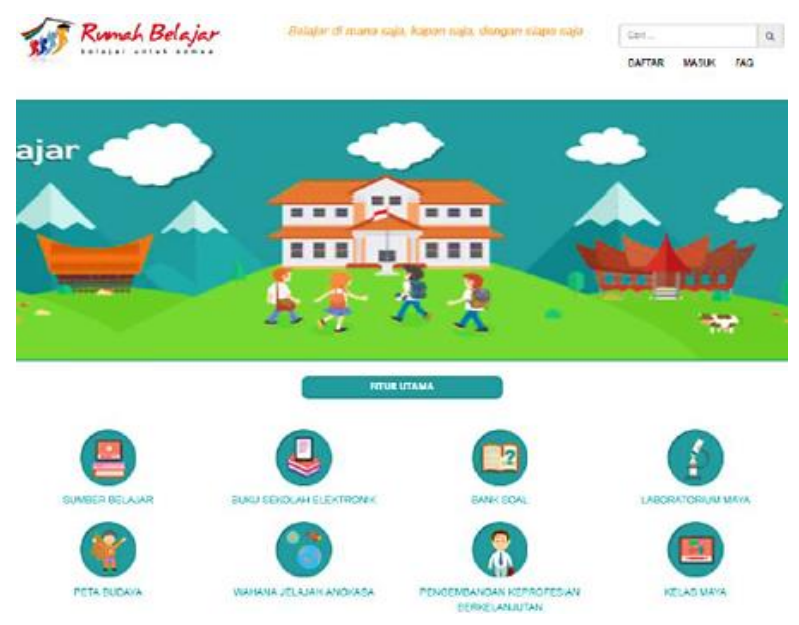

Gambar 5. Website/Aplikasi Rumah Belajar

Tim penyuluhan dan pengabdian ini tidak hanya fokus pada rumah belajar, ada banyak media lain yang diajarkan untuk alat belajar pendukung seperti google classroom, Ruangguru, dan beberapa media online lainnya. Google classroom juga aplikasi pembelajaran online sebagai pengganti kelas offline. Teori dan praktek diajarkan kepada peserta pengabdian mulai dari prosedur untuk login/registrasi sampai penggunaan aplikasi.

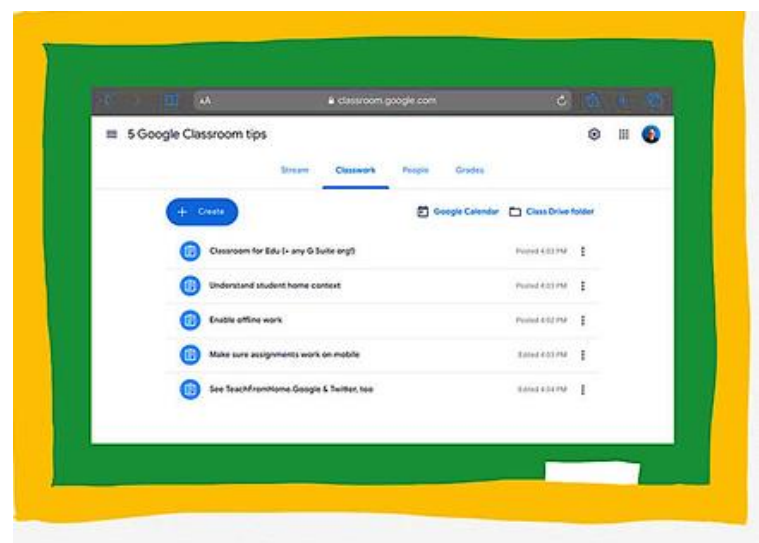

Gambar 6. Tampilan Google Classroom
Ruangguru adalah salah satu mitra pemerintah khususnya pemerintah daerah untuk meningkatkan kualitas pendidikan anak-anak bangsa. Ruangguru juga menyediakan banyak fitur pembelajaran sesuai kurikulum dan menarik seperti ruang belajar, ruang les online, digital boot camp, ruang uji, ruang les, serta ruang kelas (Langi et al., 2019).

Media pembelajaran online disinyalir sangat efektif dalam memberikan pemahaman belajar-mengajar siswa baik jenjang dasar maupun perguruan tinggi terutama di masa pandemi covid-19 saat ini. Kreatifitas guru, orang tua, serta siswa/mahasiswa harus terus didukung dengan motivasi, pengetahuan/pengalaman, serta peringkat pendukungseperti handphone/laptop yang memadai (Ariati \& Andriani, 2020; Ginting \& Kurniawan, 2020).

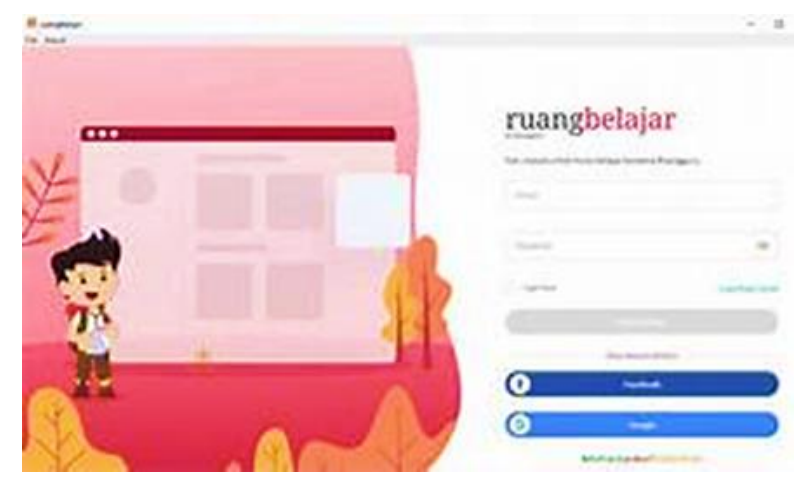

Gambar 7. Halaman Utama Website/Aplikasi

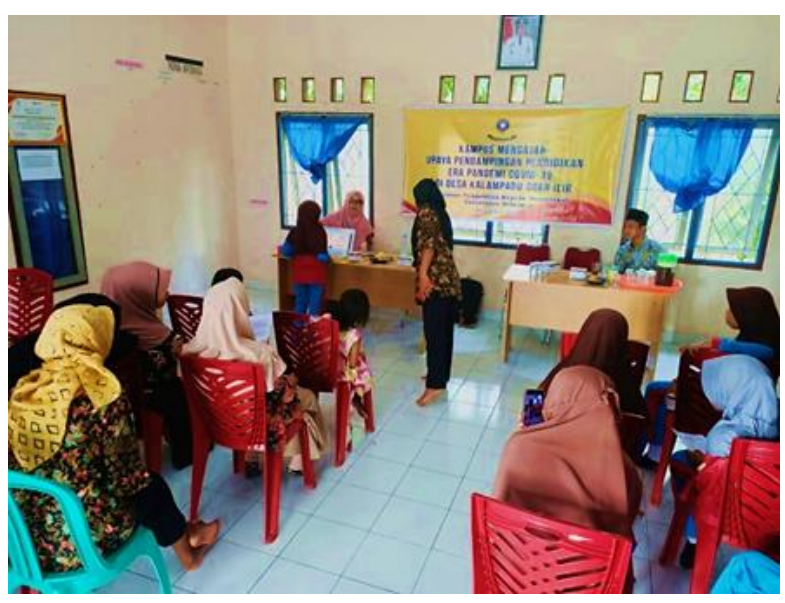

Gambar 8. Praktek Menggunakan Media Pembelajaran Online 
Tabel II. Kegiatan Pengabdian kepada Masyarakat di Desa Kalampadu

\begin{tabular}{|c|c|c|c|c|}
\hline No & Tahapan Kegiatan & Narasumber & Peserta & Materi Pengabdian \\
\hline 1 & $\begin{array}{l}\text { Pelaksanaan } \\
\text { pengabdian }\end{array}$ & $\begin{array}{l}\text {-Yulasteriyani, } \\
\text { M.Sos. } \\
\text {-Isma Nurillah, } \\
\text { S.H., M.H. } \\
\text {-Mahasiswa }\end{array}$ & $\begin{array}{l}-5 \text { orang siswa-siswi SDN } 08 \text { Muara Kuang } \\
-2 \text { orang guru SDN } 08 \text { Muara Kuang } \\
-2 \text { orang guru PAUD } \\
-2 \text { orang guru TPA } \\
-3 \text { orang tokoh masyarakat } \\
-2 \text { orang karang taruna } \\
-10 \text { orang perangkat desa } \\
-6 \text { orang kader posyandu dan lansia }\end{array}$ & $\begin{array}{l}\text {-Sosialisasi peran penting pendidikan } \\
\text {-Cara dan motivasi pendidikan } \\
\text {-Cara dan motivasi pendidikan era covid-19 } \\
\text {-Praktek penggunaan aplikasi pembelajaran } \\
\text { di android seperti rumah belajar, google } \\
\text { classroom, ruang guru, dan lain sebagainya). }\end{array}$ \\
\hline 2 & $\begin{array}{l}\text { Pelaksanaan } \\
\text { pengabdian }\end{array}$ & $\begin{array}{l}\text {-Yulasteriyani, } \\
\text { M.Sos. } \\
\text {-Isma Nurillah, } \\
\text { S.H., M.H. } \\
\text {-Mahasiswa }\end{array}$ & $\begin{array}{l}-5 \text { orang siswa-siswi SDN } 08 \text { Muara Kuang } \\
-2 \text { orang guru SDN } 08 \text { Muara Kuang } \\
-2 \text { orang guru PAUD } \\
-2 \text { orang guru TPA }\end{array}$ & $\begin{array}{l}\text {-Siswa belajar dengan pengawasan tim } \\
\text { pengabdian } \\
\text {-Siswa belajar menggunakan aplikasi } \\
\text { pembelajaran dengan pengawasan tim } \\
\text { pengabdian }\end{array}$ \\
\hline 3 & Pasca pengabdian & $\begin{array}{l}\text {-Kegiatan } \\
\text { mandiri }\end{array}$ & $\begin{array}{l}\text {-Siswa-siswi SDN } 08 \text { Muara Kuang } \\
\text {-Guru SDN 08 Muara Kuang } \\
\text {-Guru PAUD } \\
\text {-Orang tua siswa }\end{array}$ & $\begin{array}{l}\text {-Budaya belajar yang baik } \\
\text {-Siswa sadar dan termotivasi dalam belajar } \\
\text {-Siswa dapat menggunakan aplikasi belajar } \\
\text { di android secara mandiri } \\
\text {-Orang tua dan guru mendukung proses } \\
\text { belajar anak/siswa } \\
\text {-Kreatifitas pendampingan belajar oleh } \\
\text { orang tua dan guru } \\
\text {-Wifi gratis dari pemerintah desa di Sekolah } \\
\text { dan kantor desa }\end{array}$ \\
\hline
\end{tabular}

\section{KESIMPULAN}

Kegiatan pengabdian ini disambut baik oleh masyarakat dan peserta pengabdian di Desa Kalampadu. Kegiatan ini tergolong sangat sukses baik dari tahap awal hingga akhir acara. Kegiatan ini dapat memberikan pemahaman dan penyadaran nilai-norma pendidikan umumnya kepada anak-anak sekolah, orang tua, dan pendidik (guru) serta khususnya kepada para peserta pengabdian di Desa Kalampadu. Setelah kegiatan dilakukan peserta sangat antusias dan termotivasi untuk belajar-mengajar dengar efektif dan efesien. Kegiatan belajar-mengajar yang baik dapat meningkatkan kualitas pendidikan dan sumber daya manusia yang berwawasan luar dan berakhlak mulia. Rangkaian kegiatan pengabdian kepada masyarakat ini sarat dengan praktek dari teori struktural fungsional Parsons. Setiap rangkaian acara dari awal sampai akhir sangat cocok dengan skema AGIL dalam proses sosialisasi dan internalisasi nilainorma pendidikan. Kata sambutan sebagai proses readaptasi, penyampaian materi sesuai dengan skema reintegrasi, serta proses tanya-jawab dan interaktif menerapkan semua unsur adapatasi-pencapaian tujuan- integrasi-pemeliharaan pola. Media pembelajaran online adalah output dari kegiatan pengabdian. Pada akhirnya, kegiatan pengabdian masyarakat yang dilakukan ini menyumbang integrasi nilai-normal ke dalam sistem sosial-pendidikan masyarakat Desa Kalampadu. Sistem pendidikan yang baik dan ideal adalah sub sistem yang teratur dalam sistem sosial-budaya masyarakat. Masyarakat di Desa Kalampadu masih jarang tersentuh oleh kegiatan-kegiatan penyuluhan maupun pengabdian masyarakat padahal realitas sosial-budaya masyarakat disini sangat menerima dan membutuhkan kegiatan-kegiatan seperti ini. Kegiatan pengabdian selanjutnya sangat cocok jika dilakukan secara kolaboratif antar beberapa bidang ilmu yang paling potensial dibutuhkan oleh masyarakat Desa Kalampadu.

\section{UCAPAN TERIMA KASIH}

Ucapan terima kasih para penulis kepada lembaga pemberi dana kagiatan pengabdian kepada masyarakat yaitu kepada LPPMP Universitas Sriwijaya. Penulis juga menyampaikan ucapan terima kasih kepada semua 
pihak yang turut membantu pelaksanaan kegiatan pengabdian ini.

\section{REFERENSI}

Ariati, N., Andriani, Y. 2020. Pengenalan Aplikasi Belajar Online di Tengah Masa. Jurnal Abdimas Mandiri. 4(2):110-116. http://dx.doi.org/10.36982/jam.v4i2.1271

Asmuni. 2020. Problematika Pembelajaran Daring di Masa Pandemi Covid-19 dan Solusi Pemecahannya. Jurnal Paedagogy. 7(4):281-288. https://doi.org/10.33394/jp.v7i4.2941

Basrowi, Juariyah, S. 2010. Analisis Kondisi Sosial Ekonomi dan Tingkat Pendidikan Masyarakat Desa Srigading, Kecamatan Labuhan Maringgai, Kabupaten Lampung Timur. Jurnal Ekonomi dan Pendidikan. 7(1):58-81. https://doi.org/10.21831/jep.v7i1.577

Cahyani, A., Listiana, I.D., Larasati, S.P.D. 2020. Motivasi Belajar Siswa SMA pada Pembelajaran Daring di Masa Pandemi Covid-19. IQ (Ilmu Al-qur'an): Jurnal Pendidikan Islam. 3(1):123-140. https://doi.org/10.37542/iq.v3i01.57

Endaryono, B.T., Djuhartono, T. 2017. Indikator Pembangunan Pendidikan Untuk Masyarakat Berkelanjutan Dengan Pendidikan Berkarakter Di Indonesia. Faktor: Jurnal Ilmiah Kependidikan. 4(3):301-306. http://dx.doi.org/10.30998/fjik.v4i3.2030

Farida, U. 2013. Pengaruh Aksesibilitas Terhadap Karakteristik Sosial Ekonomi Masyarakat Pedesaan Kecamatan Bumijawa Kabupaten Tegal. Jurnal Wilayah dan Lingkungan. 1(1):4966. https://doi.org/10.14710/jwl.1.1.49-66

Ginting, W.M., Kurniawan, H. 2020. Perancangan Aplikasi Bimbingan Belajar Dan Ujian Dengan Mengimplementasikan Streaming Online Berbasis Web Dan Android. Jurnal Mahasiswa Fakultas Teknik dan Ilmu Komputer. 1(1):394-406

Hannum, W.H., Irvin, M.J., banks, J.B., Farmer, T.W. 2009. Distance Education Use in Rural Schools. Journal of Research in Rural Education. 24(3):1-15.

Herzog, M.J.R., Pittman, R.B. 1995. Home, Family, and Community. Ingredients in the Rural Education Equation. Phi Delta Kappan. 77:113118.
Langi, E., Londa, N.S., Tulung, L. 2019. Pengaruh komunikasi media online aplikasi ruang guru PT. Ruang Raya Indonesia terhadap peningkatan prestasi belajar siswa SMA negeri 1 Manado. Acta Diurna Komunikasi. 1(3):1-16.

Maria, N.N., Chinemerem, A.N. 2019. Ensure Inclusive And Equitable Quality Education And Promote Lifelong Learning Opportunities For Achieving Sustainable Development Goals: The Role Of Libraries. International Journal of Library and Information Science Studies. 5(2):3035.

Muttaqin, Z., Wardana, A. 2018. Pendidikan multi kultural berbasis kearifan lokal (studi di SMA Negeri 1 Narmada). Harmoni Sosial: Jurnal Pendidikan IPS. 5(2):202-212. https://doi.org/10.21831/hsjpi.v5i2.10463

Niko, N., Yulasteriyani, Y. 2020. Pembangunan Masyarakat Miskin Di Pedesaan Perspektif Fungsionalisme Struktural. Muharrik: Jurnal Dakwah dan Sosial. 3(2):213-225. https://doi.org/10.37680/muharrik.v3i02.47 6

Rachmawati, Y., Ma'arif, M., Fadhillah, N., Inayah, N., Ummah, K., Siregar, M.N.F., Amalyaningsih, R., Aftannailah, F., Auliyah, A. 2020. Studi Eksplorasi Pembelajaran Pendidikan IPA Saat Masa Pandemi COVID-19 Di UIN Sunan Ampel Surabaya. Indonesian Journal of Science Learning. https://doi.org/10.15642/ijsl.v1i1.633

Rasyid, M.R. 2015. Pendidikan Dalam Perspektif Teori Sosiologi. Auladuna: Jurnal Pendidikan Dasar Islam. 2(2):274-286.

Ritzer, G. 2010. Sociological Theory Eighth ( $8^{\text {th }}$ ) Edition. New York: McGraw-Hill Humanities/Social Sciences/Language.

Utami, Y.P., Dewi, P.S. 2020. Model Pembelajaran Interaktif SPLDV Dengan Aplikasi Rumah Belajar. Mathema: Jurnal Pendidikan Matematika. 2(1):24-31. https://doi.org/10.33365/jm.v2i1.572

Yulasteriyani, Y., Randi, R., Hasbi, M. 2019. Kemiskinan Masyarakat di Indonesia: Perspektif Sosiologi Islam dan Fenomenologi Barat. Intizar. 25(2):77-86. https://doi.org/10.19109/intizar.v25i2.4463 
Yulasteriyani. 2018. Kemiskinan Masyarakat Petani Sawah Tadah Hujan Di Desa Kalampadu, Muara Kuang, Ogan Mir, Sumatera Selatan. Tesis. Bandung: Universitas Padjadjaran.

Zid, M., Alkhudri, A.T. 2016. Sosiologi pedesaan: teoretisasi dan perkembangan kajian pedesaan di Indonesia. Jakarta: Rajawali Press. 